(C) 2017 by the Arizona Board of Regents on behalf of the University of Arizona. This is an Open Access article, distributed under the terms of the Creative Commons Attribution licence (http://creativecommons.org/ licenses/by/4.0/), which permits unrestricted re-use, distribution, and reproduction in any medium, provided the original work is properly cited.

\title{
DATING HUMAN SETTLEMENT IN THE EAST-CENTRAL TIBETAN PLATEAU DURING THE LATE HOLOCENE
}

\author{
LeLe Ren ${ }^{1} \cdot$ GuangHui Dong ${ }^{1 *} \cdot$ HaiMing $\operatorname{Li}^{1} \cdot \operatorname{Dave~Rhode}^{2} \cdot \operatorname{Rowan~K~Flad}^{3} \bullet$

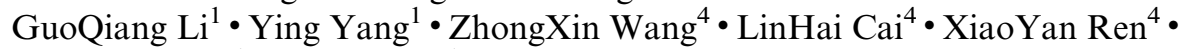 \\ DongJu Zhang ${ }^{1} \cdot \mathrm{FaHu} \mathrm{Chen}^{1}$ \\ ${ }^{1}$ MOE Key Laboratory of Western China's Environmental Systems, College of Earth \& Environmental Sciences,
Lanzhou University, Lanzhou, Gansu Province, 730000, China.
${ }^{2}$ Division of Earth and Ecosystem Sciences, Desert Research Institute, Reno, NV 89512, USA.
${ }^{3}$ Department of Anthropology, Harvard University, Cambridge, MA 02138, USA.
${ }^{4}$ Qinghai Provincial Institute of Cultural Relics and Archaeology, Xining, Qinghai Province, 810007, China.
}

\begin{abstract}
Recent multidisciplinary research indicates that prehistoric agriculture innovation promoted permanent human settlements of areas up to $3400 \mathrm{~m}$ above sea level (asl) in the northern Tibetan Plateau, but when and how ancient humans extensively occupied areas above that altitude remains uncertain. In this paper, we investigated 12 archaeological sites situated above $3600 \mathrm{~m}$ asl in the Yushu autonomous prefecture, east-central Tibetan Plateau, to explore this issue. We determined the ages of five sites using the radiocarbon $\left({ }^{14} \mathrm{C}\right)$ dating method and identified animal bones sampled from three sites. The dating results show that humans occasionally occupied the Yushu area around $900 \mathrm{BC}$, and permanently inhabited the area between AD 540 and 1620. Preliminary faunal identifications indicate human-raised livestock including yak, sheep, and horse during the latter period. Stone-constructed tombs and rock painting were found at some investigated sites, suggesting humans perhaps engaged in a pastoral lifestyle during the very late Holocene in the high altitude Yushu area, where nomadic livestock production remains the current primary subsistence strategy focus.
\end{abstract}

KEYWORDS: animal remains, east-central Tibetan Plateau, late Holocene, rock paintings, radiocarbon dating, sandtempered brown ceramics, stone-constructed tombs.

\section{INTRODUCTION}

The history and strategies for achieving permanent human colonization on the Tibetan Plateau, the highest plateau on the earth, have been intensively studied in recent years (Madsen et al. 1998, 2006; Zhang and Li 2002; Brantingham et al. 2003, 2007; Aldenderfer 2006, 2011; Brantingham and Gao 2006; Rhode et al. 2007; Yuan et al. 2007; Sun et al. 2012; Tang et al. 2013; Guedes 2015; Guedes et al. 2014, 2015; Chen et al. 2015). Archaeological investigation and optical dating indicate that foragers possibly reached $4200 \mathrm{~m}$ above sea level (asl) around 20,000 BP (Zhang and Li 2002), and definitely occupied areas above $3200 \mathrm{~m}$ asl after 15,000 BP (Brantingham and Gao 2006; Madsen et al. 2006; Brantingham et al. 2007; Rhode et al. 2007, 2014; Meyer et al. 2017). Both archaeological and genetic research reveals that people began to inhabit the Tibetan Plateau on a large scale during the late Neolithic and Bronze Age periods (Bureau of National Cultural Relics 1996, 2010; Brantingham et al. 2007; Zhao et al. 2009; Dong et al. 2014; Qiu et al. 2015; Barton 2016). Recent study further demonstrates that the development of millet agriculture in the western Loess Plateau promoted human expansion into the northeastern margin of the Tibetan Plateau, and that the millet farming communities mainly settled below $2500 \mathrm{~m}$ asl between 5200 and $3600 \mathrm{BP}$, at relatively low elevations because of the cold-sensitivity of millet crops. The introduction and cultivation of cold-resistant barley and wheat facilitated more permanent human settlement up to $3400 \mathrm{~m}$ asl on the northeast Tibetan Plateau after 3600 BP (Chen et al. 2015), although Guedes et al. (2015) questioned the mechanism by which barley and wheat arrived at the high altitudes. When and how humans intensively colonized areas above $3400 \mathrm{~m}$ asl, where pastoral production practice is the primary subsistence strategy nowadays (Miller 1999), still remain unclear.

\footnotetext{
*Corresponding author. Email: ghdong@1zu.edu.cn.
} 
Archaeobotanical and zooarchaeological analyses have shed light on human subsistence strategies during prehistoric times on the Tibetan Plateau (Huang 1980; IA, CASS \& CRBTAR 1999; Schlütz and Lehmkuhl 2009; Zhao 2009; Guedes et al. 2013, 2014, 2015; Miehe et al. 2014; Chen et al. 2015; Guedes 2015; Dong et al. 2016a, 2016b), and promoted our understanding of how prehistoric humans adapted to this harsh environment. However, the prehistoric sites so far examined are mostly located in the northeastern Tibetan Plateau, and in a few scattered places on the southern Tibetan Plateau, roughly along the ancient Tang-Tibet road (Figure 1b; Chen 1989), which historically was the most important passageway for interregional interaction between the Yellow River valley and Lhasa. The Yushu area of the east-central Tibetan Plateau, with average elevation above $4200 \mathrm{~m}$ asl, is situated at a key position of the Tang-Tibet ancient road, but the chronology and biological remains from archaeological sites in this area have been rarely reported.

A total of 17 late prehistoric sites above $3600 \mathrm{~m}$ asl were found during the second national archaeological survey in Yushu prefecture (Bureau of National Cultural Relics 1996), and were classified as Bronze Age sites mainly based on archaeological remains such as sand-tempered brown ceramics and stone-constructed tombs. The chronological data, especially absolute dating, to the human settlement history of the high altitude regions of the Tibetan Plateau is extremely important to understanding the prehistoric and historical process of peopling on the Tibetan Plateau. However, no reliable dates of those sites have been published. Although dating according to archaeological features is the basis of archaeological research, they are not as objective as absolute dates. For example, if people in one region continued to use a pottery style later than another, archaeologists may date them to the same period because of their style.

Only absolute dates can clarify the actual situation. So estimating the ages of sites on the Tibetan Plateau based on typological archaeological remains alone must be used with caution (Sun 2012; Hudson et al. 2014; Liu et al. 2016). Radiocarbon $\left({ }^{14} \mathrm{C}\right)$ dating of animal and plant remains samples is relatively reliable for the past 50,000 years (Geyh et al. 1997), and has been widely used to establish the chronology of archaeological sites (Guo et al. 2001, 2005; Liu et al. 2005; Cherkinsky and Quezada 2014; Salazar-García et al. 2016). In this paper, we study the chronology and subsistence strategy of ancient human colonization in the Yushu area, with the application of archaeological investigation, ${ }^{14} \mathrm{C}$ dating, identification of animal bones, and the comparison between written documents, to further explore when and how ancient human colonized and adapted to high altitudes in the Yushu area. Our results show that humans occasionally inhabited the Yushu area around $900 \mathrm{BC}$, and more permanently occupied the area between AD 540 and 1620 , likely engaging in a kind of subsistence practice consistent with pastoralism.

\section{STUDY AREA}

The Yushu Tibetan Autonomous Prefecture $\left(31^{\circ} 45^{\prime}-36^{\circ} 10^{\prime} \mathrm{N}, 89^{\circ} 27^{\prime}-97^{\circ} 39^{\prime} \mathrm{E}\right)$ is located in southern Qinghai Province, the east-central Tibetan Plateau (Figure 1). It stretches $738 \mathrm{~km}$ from west to east and $405 \mathrm{~km}$ from south to north, with the mean altitude above $4200 \mathrm{~m}$ asl and the minimum altitude $3610 \mathrm{~m}$ asl. The area of Yushu autonomous prefecture is $267,000 \mathrm{~km}^{2}$, accounting for $32.7 \%$ of the total area of Qinghai Province (Zhang 2009). The mean annual temperature is $-0.8^{\circ} \mathrm{C}$ and the mean annual precipitation is $463.7 \mathrm{~mm}$. More specifically, the mean annual temperature and precipitation in Nangqian and Yushu counties of Yushu autonomous prefecture (the focal areas of the data reported here) are $4.59^{\circ} \mathrm{C}$ and $3.75^{\circ} \mathrm{C}$, and $451 \mathrm{~mm}$ and $402 \mathrm{~mm}$, respectively (http://data.cma.cn/en). Vast meadowlands in the region have supported a livelihood based on pastoral livestock production and supplemented by agriculture mainly based on barley (Hu 1995). Huge numbers of sheep, goats, yaks, and horses 

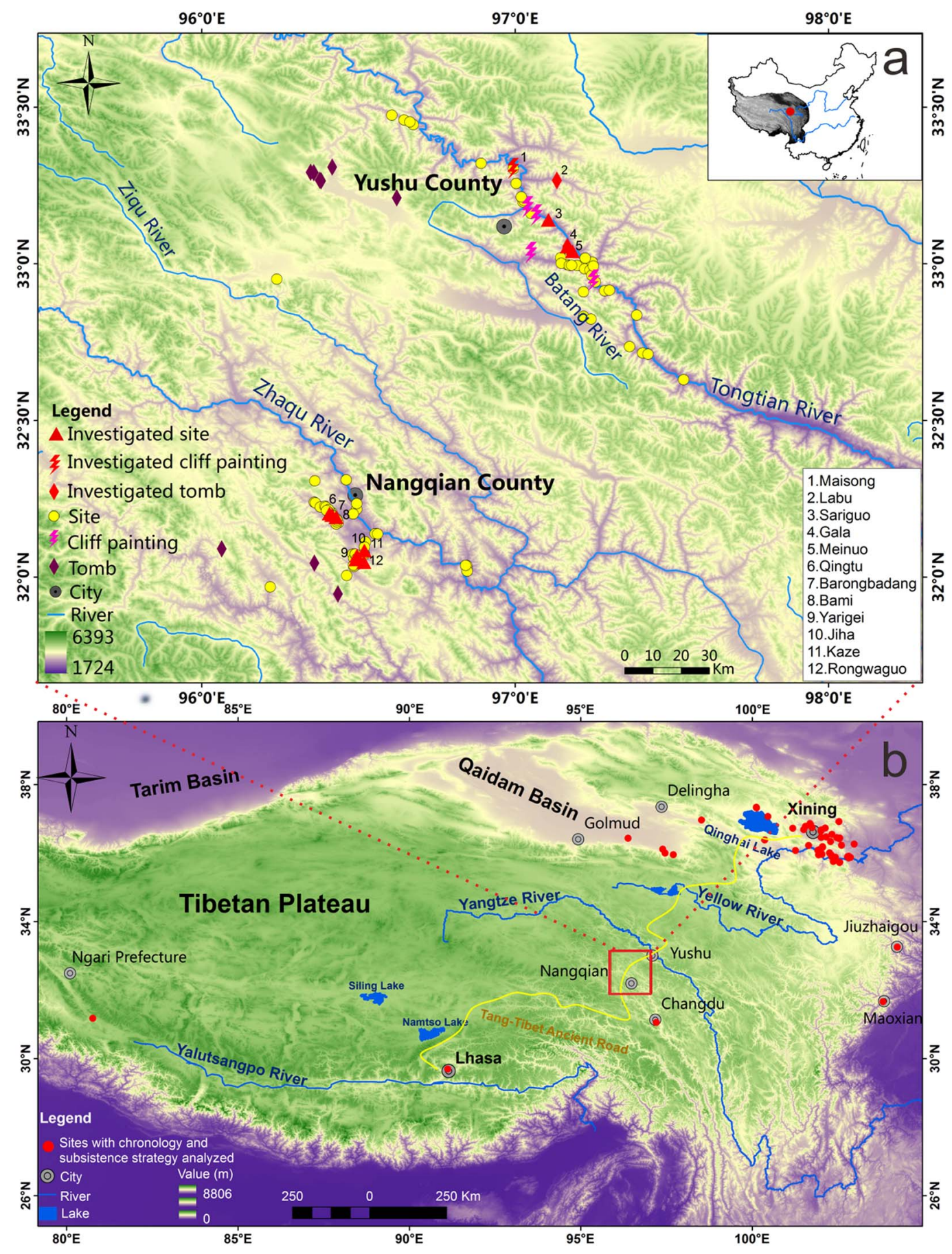

Figure 1 Overview of the study area: (a) location of the study area and the investigated sites; (b) archaeological sites with chronology and subsistence strategy analyzed on the Tibetan Plateau. 
thrive in wide alpine meadows. The pastoral Zang (Tibetan) peoples account for $95.3 \%$ of the total population in the Yushu autonomous prefecture (Shi 1988).

Six counties are administered by the Yushu autonomous prefecture, including Yushu, Nangqian, Zaduo, Chengduo, Qumalai, and Zhiduo. According to the second national archaeological survey, all 17 Bronze period sites reported in the Yushu autonomous prefecture are located in the Yushu and Nangqian counties (Bureau of National Cultural Relics 1996).

\section{MATERIALS AND METHODS}

Based on the consultation and guidance from local archaeologists who participated in the second archaeological survey in the Yushu region, we investigated 12 archaeological sites where exposed archaeological deposits or sand-tempered brown ceramics were found during field work in 2012 (Figure 1a), including 10 settlement sites, one tomb, and one rock painting site. Half of these 12 sites were reported as Bronze period sites in the second archaeological survey in Qinghai Province (Bureau of National Cultural Relics 1996). The remaining six sites were not among the 17 sites listed in the second archaeological survey but instead were newly found as part of this investigation. The investigation processes at all sites were carried out according to the latest field protocol enacted by Bureau of National Cultural Relics (2009). The specific methods used during the survey including observing stratigraphic section and collecting surface remains. Based on the background information about known sites, especially the specific latitude and longitude, we could find them readily with handheld GPS, and then collected cultural remains including pottery sherds, animal bones, lithics and charcoal from the surface or exposed sections. All information including the location, elevation, and archaeological remains observed on feature or depositional contexts was recorded and photographed in detail for every site we investigated (most information is shown in Figure 2, Figure 4, and Table 1).

There are six bone samples and three charcoal samples collected for ${ }^{14} \mathrm{C}$ dating from five sites, including Labu, Yarigei, Barongbadong, Gala, and Rongwaguo (Table 1). Three of these bone samples were obtained from the Barongbadong and Gala sites, where they were associated with sand-tempered brown ceramics in surface exposures. All other samples were obtained from cultural deposits or tombs at other archaeological sites. Specifically, one bone and one charred sheep dropping were sampled for ${ }^{14} \mathrm{C}$ dating from beneath one slabstone of Labu tomb where there were no obvious disturbance signals after burial. The two remaining charcoal samples were all acquired from undisturbed strata, one of which was found in a thin cultural layer at the Rongwaguo site and the other one in the burned layer of exposed section at the Gala site. Four bone samples and two charcoal samples were dated by accelerator mass spectrometry (AMS) at Peking University, China, and the other two bone samples and one charred sheep dropping sample were dated by AMS at Beta Analytic, Miami, USA. The IntCal13 curve (Reimer et al. 2013) and the Libby half-life of $5568 \mathrm{yr}$ were used in the tree-ring calculation of all dates, with the calibration performed using the OxCal 4.2.3 program (Bronk Ramsey and Lee 2013). All ages are reported as "Cal $\mathrm{BC}$ or $\mathrm{AD}$. ."

We also sampled well-preserved animal bones from exposed tombs or cultural deposits at Gala, Yarigei, and Labu sites during archaeological investigations. Taxon identification was made in the Key Laboratory of Western China's Environmental Systems (Ministry of Education) in Lanzhou University based on the morphological characters of the bones. For further confirmation, we compared the animal bones from the Yushu region with the modern and ancient zoological specimens held in the Zooarchaeology Laboratory, Institute of Archaeology, Chinese Academy of Social Sciences. 

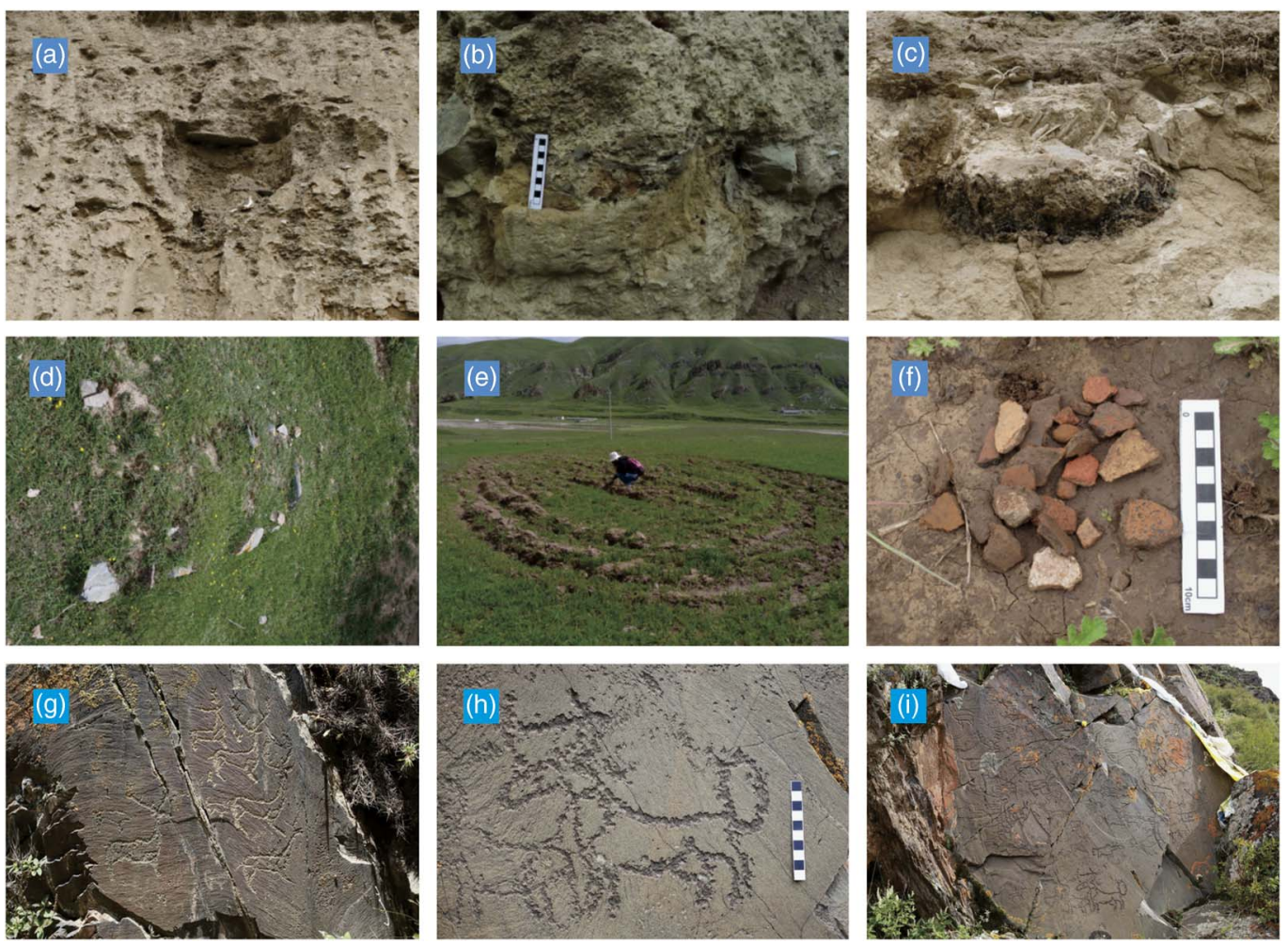

Figure 2 Field investigation in archaeological sites in the Yushu and Nangqian counties: (a) and (b) stoneconstructed tomb and cultural layer in the Gala site; (c) stone-constructed tomb in the Labu site; (d) exposed stone-constructed tomb on the ground of the Sariguo site; (e) sampling location in the Barongbadang site; (f) sandtempered brown ceramics of the Bami site; (g), (h), and (i) cliff painting in Maisong site.

\section{RESULTS}

\section{Archaeological Remains and Radiocarbon Dates}

In Yushu County, five sites were investigated along the Tongtian River, including Gala, Labu, Meinuo, Sariguo, and Maisong (Figure 1a). At the Gala site (3650 $\mathrm{m}$ asl), a stone-constructed tomb, a cultural layer (Figure $2 \mathrm{a}$ and $\mathrm{b}$ ) and a pit tomb were found. The stone-constructed tomb was about $80 \mathrm{~cm}$ high and $50 \mathrm{~cm}$ wide, sealed by two slabstones on top and bottom (Figure 2a). A few human and animal bones were exposed in the tomb, and one human bone was dated to cal AD 1320-1440 (Figure 3; Table 1). Another fragment of bone identified as human from the pit tomb in the site was dated to $1000-850 \mathrm{cal} \mathrm{BC} \mathrm{(Figure} \mathrm{3;} \mathrm{Table} \mathrm{1).} \mathrm{One} \mathrm{burned} \mathrm{sediment} \mathrm{and}$ charcoal layer was also found (Figure 2b). This layer was about $3 \mathrm{~cm}$ thick and $3 \mathrm{~m}$ wide in the exposed section and, possibly is the remains of a house floor. One fragment of sand-tempered brown ceramic and an animal bone were found in the sedment above the possible floor. A charcoal sample from the burned layer was dated to cal AD 1440-1620 (Figure 2b; Table 1).

At the Labu site (3893 m asl), four partially buried slabstones were found, beneath one of which was a nearly intact animal skeleton and abundant charred materials including charcoal and carbonized sheep droppings (Figure 2c). A sample of charred sheep dropping and a piece of bone yielded dates of cal AD 550-650 and cal AD 540-630, respectively (Figure 3; Table 1). 


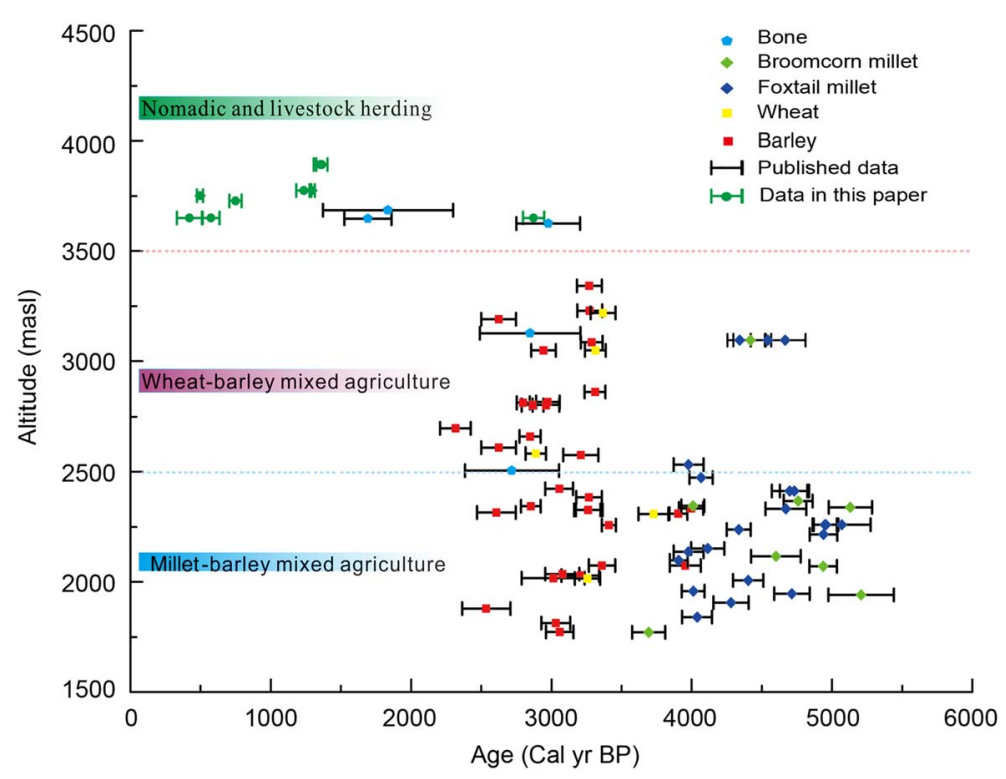

Figure $3{ }^{14} \mathrm{C}$ dates of investigated sites in Yushu area and their comparison with ${ }^{14} \mathrm{C}$ dates of domesticated plants and animals from other prehistoric sites on the Tibetan Plateau. Blue and red dotted lines indicate the current upper limit altitude of millet cultivation and intensive barley cultivation on the Tibetan Plateau. (Colors refer to online version.)

At the Meinuo (3740 $\mathrm{m}$ asl) and Sariguo (3630 $\mathrm{m}$ asl) sites, plentiful sand-tempered brown ceramics were found on the ground surface, and a stone-constructed tomb was found exposed at the Sariguo site (Figure 2d). However, no exposed cultural layer or reliable dating material was found at those two sites. Likewise, no datable samples were recovered from the Maisong site ( $3730 \mathrm{~m}$ asl), while rock paintings of animals including dogs and deer were found on a stone cliff (Figure $2 \mathrm{~g}$ and $\mathrm{h}$ ).

In Nangqian County, seven sites including Qingtu, Barongbadang, Bami, Rongwaguo, Kaze, Jiha, and Yarigei were investigated (Figure 1a). The Qingtu (3740 $\mathrm{m}$ asl), Barongbadang (3728 $\mathrm{m}$ asl) and Bami (3750 $\mathrm{m}$ asl) sites are adjacent to each other on a grassy slope. Abundant sand-tempered brown ceramics were found on the ground surface at each site (Figure 2f), but no ceramic sherds were in an exposed buried context from any of those three sites. At the Barongbadang site, ploughed fields yielded a mass of exposed sand-tempered brown ceramics and weathered bones. One piece of bone was dated to cal AD 1160-1250 (Figure 3; Table 1). At the Rongwaguo (3751 m asl), Kaze (4070 m asl), Jiha (3764 $\mathrm{m}$ asl), and Yarigei ( $3774 \mathrm{~m}$ asl) sites, abundant sand-tempered brown ceramics were found on the surface, but only a thin ( $4 \mathrm{~cm}$ thick) cultural layer was found at the Rongwaguo site, from which a piece of charcoal was dated to cal AD 1430-1480 (Figure 3; Table 1). Buried stone walls were discovered at the Rongwaguo and Yarigei sites. At the Yarigei site, many weathered animal bones in conjunction with sand-tempered brown ceramics were found exposed in a construction area. Two pieces of bones were dated respectively to cal AD 630-680 and cal AD 660-770 (Figure 3; Table 1). We did not obtain reliable dating materials from the Kaze and Jiha sites.

\section{Faunal Remains}

The analysis of animal remains collected during the archaeological survey in Yushu prefecture indicated that sheep (Ovis aries), yak (Bos grunniens), and horse (Equus ferus caballus) were present at the Gala, Labu, and Yarigei sites (photographs in Figure 4; Table 2). At Gala, two pieces of sheep bones (Figure 4c) (from at least one individual), and two yak bones 
Table 1 Calibrated ${ }^{14} \mathrm{C}$ dates of investigated sites in the Yushu area.

\begin{tabular}{|c|c|c|c|c|c|c|c|}
\hline \multirow[b]{2}{*}{ Lab nr } & \multirow[b]{2}{*}{ Material dated } & \multirow{2}{*}{$\begin{array}{l}\text { Archaeological } \\
\text { context }\end{array}$} & \multicolumn{2}{|l|}{ Site } & \multirow[b]{2}{*}{${ }^{14} \mathrm{C}$ age (BP) } & \multicolumn{2}{|l|}{ Calibrated age } \\
\hline & & & Name & Elevation (m) & & $1 \sigma(68.2 \%)$ & $2 \sigma(95.4 \%)$ \\
\hline BA121493 & Bone & Tomb & Labu & 3893 & $1485 \pm 20$ & $\begin{array}{l}560 \mathrm{AD}(68.2 \%) \\
600 \mathrm{AD}\end{array}$ & $\begin{array}{l}540 \mathrm{AD}(95.4 \%) \\
630 \mathrm{AD}\end{array}$ \\
\hline Beta331313 & $\begin{array}{l}\text { Charred sheep } \\
\text { dropping }\end{array}$ & Tomb & Labu & 3893 & $1470 \pm 30$ & $\begin{array}{l}570 \mathrm{AD}(68.2 \%) \\
630 \mathrm{AD}\end{array}$ & $\begin{array}{l}550 \mathrm{AD}(95.4 \%) \\
650 \mathrm{AD}\end{array}$ \\
\hline BA121491 & Bone & Cultural layer & Yarigei & 3774 & $1375 \pm 20$ & $\begin{array}{l}650 \mathrm{AD}(68.2 \%) \\
660 \mathrm{AD}\end{array}$ & $\begin{array}{l}630 \mathrm{AD}(95.4 \%) \\
680 \mathrm{AD}\end{array}$ \\
\hline Beta327242 & Bone & Cultural layer & Yarigei & 3774 & $1300 \pm 30$ & $\begin{array}{l}670 \mathrm{AD}(46.4 \%) \\
710 \mathrm{AD} \\
750 \mathrm{AD}(21.8 \%) \\
760 \mathrm{AD}\end{array}$ & $\begin{array}{l}660 \text { AD }(64.4 \%) \\
730 \text { AD } \\
740 \text { AD }(31.0 \%) \\
770 \text { AD }\end{array}$ \\
\hline BA121489 & Bone & Surface & Barongbadang & 3728 & $855 \pm 20$ & $\begin{array}{l}1170 \mathrm{AD}(68.2 \%) \\
1210 \mathrm{AD}\end{array}$ & $\begin{array}{l}1160 \mathrm{AD}(95.4 \%) \\
1250 \mathrm{AD}\end{array}$ \\
\hline BA121485 & Charcoal & Cultural layer & Rongwaguo & 3751 & $430 \pm 20$ & $\begin{array}{l}1440 \text { AD }(68.2 \%) \\
1460 \text { AD }\end{array}$ & $\begin{array}{l}1430 \mathrm{AD}(95.4 \%) \\
1480 \mathrm{AD}\end{array}$ \\
\hline Beta327244 & Bone & Surface & Gala & 3650 & $540 \pm 30$ & $\begin{array}{l}1330 \mathrm{AD}(13.5 \%) \\
1340 \mathrm{AD} \\
1400 \mathrm{AD}(54.7 \%) \\
1430 \mathrm{AD}\end{array}$ & $\begin{array}{l}1320 \mathrm{AD}(29.8 \%) \\
1350 \mathrm{AD} \\
1390 \mathrm{AD}(65.6 \%) \\
1440 \mathrm{AD}\end{array}$ \\
\hline BA121484 & Charcoal & Cultural layer & Gala & 3650 & $395 \pm 25$ & $\begin{array}{l}1450 \mathrm{AD}(61.2 \%) \\
1490 \mathrm{AD} \\
1600 \mathrm{AD}(7.0 \%) \\
1610 \mathrm{AD}\end{array}$ & $\begin{array}{l}1440 \text { AD }(79.5 \%) \\
1520 \text { AD } \\
1590 \text { AD }(15.9 \%) \\
1620 \text { AD }\end{array}$ \\
\hline BA121492 & Bone & Surface & Gala & 3650 & $2780 \pm 20$ & $\begin{array}{l}970 \mathrm{BC}(17.1 \%) \\
960 \mathrm{BC} \\
940 \mathrm{BC}(51.1 \%) \\
900 \mathrm{BC}\end{array}$ & $\begin{array}{l}1000 \mathrm{BC}(87.8 \%) \\
890 \mathrm{BC} \\
880 \mathrm{BC}(7.6 \%) \\
850 \mathrm{BC}\end{array}$ \\
\hline
\end{tabular}



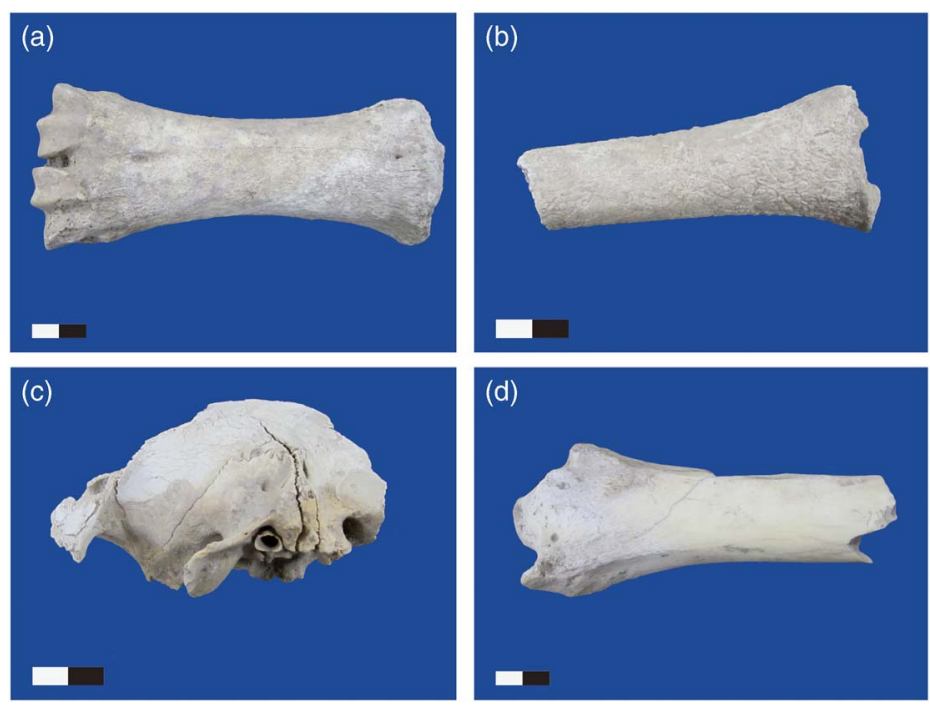

Figure 4 Photographs of animal remains from the investigated sites in Yushu areas: (a) and (d) are identified as yak, (b) is identified as horse, and (c) is identified as sheep.

Table 2 Animal remains from investigated sites in the Yushu area.*

\begin{tabular}{|c|c|c|c|c|c|c|c|}
\hline Context & Species & Element & Part & Symmetry & Fusion & MNI & NISP \\
\hline GL(2) & Ovis aries & Skull & & Right & & 1 & 2 \\
\hline GL(2) & Ovis aries & Maxillary & & Right & & & \\
\hline GL(2) & Bos grunniens & Metacarpale & & Right & Both end fused & 1 & 1 \\
\hline GL12 section & Large mammal & Limb bone & & & & 1 & 1 \\
\hline Gala SGZ-2 & Bos grunniens & Tibia & Distal & Right & Distal fused & 1 & 1 \\
\hline Labu SGZ & Medial mammal & Rib & & & Unfused & 1 & 1 \\
\hline $\begin{array}{l}\text { YRG } \\
\text { stratum }\end{array}$ & $\begin{array}{l}\text { Equus ferus } \\
\text { caballus }\end{array}$ & Radius & Distal & Right & $\begin{array}{l}\text { Unfused without } \\
\text { joint }\end{array}$ & 2 & 2 \\
\hline $\begin{array}{l}\text { YRG } \\
\text { stratum }\end{array}$ & $\begin{array}{l}\text { Equus ferus } \\
\text { caballus }\end{array}$ & Radius & Distal & Right & $\begin{array}{l}\text { Unfused without } \\
\text { joint }\end{array}$ & & \\
\hline
\end{tabular}

*MNI = minimum number of individuals; NISP = number of identified specimens.

(Figure 4a and d) from two separate individuals, were identified. A rib from an unidentified medium-sized mammal was found in the stone-constructed tomb at Labu. In addition, two foal skeletons (Figure 4b) were identified based on two pieces of unfused distal radius from the cultural strata at Yarigei in Nangqian County. Given the late date of investigated sites and morphological characteristics of bones, all animals discovered in the Yushu region are thought to be domesticated herd species.

\section{DISCUSSION}

\section{When Did Humans Colonize the Yushu Area?}

According to the third national archaeological survey, dozens of archaeological sites above $3600 \mathrm{~m}$ asl in Yushu and Nangqian counties (Figure 1a, unpublished data) were classified to the 
Bronze Age on the basis of the scattered sand-tempered brown ceramics found at these sites. In eastern Qinghai Province, sand-tempered brown ceramics are the typical pottery found at Bronze Age sites; for example, abundant sand-tempered brown ceramics were found in Kayue and Xindian Bronze Age sites in the upper Yellow River valley, the ages of which range approximately between 1600 and 300 BC (3600-2300 cal yr BP) (Dong et al. 2013). However, of the 12 investigated sites in the Yushu area, only one sample of human bone from the Gala site was ${ }^{14} \mathrm{C}$ dated to the Bronze Age, while the other eight dates correspond to historic periods (From Wei Jin Southern and Northern Dynasties to Ming Dynasty) in central China (Table 1; Figure 3). These dates suggest that people perhaps occupied the Yushu area sporadically between 1000-850 cal BC; they also suggest that determining a Bronze Age chronology for archaeological sites in the area solely based on the presence of sand-tempered brown ceramics cannot be warranted.

The mitochondrial genome evidences have showed that the initial Paleolithic inhabitants settled on the Tibetan Plateau successfully (Zhao et al. 2009; Qi et al. 2013), and two early human population expansions occurred on the Tibetan Plateau during the early-Neolithic age and the late-Holocene that coincided with the establishment of farming and yak pastoralism (Qiu et al. 2015). In the northeastern Tibetan Plateau, Kayue and Nuomuhong societies had successfully settled above $3400 \mathrm{~m}$ asl since $1600 \mathrm{BC}$ (3600 BP) (Chen et al. 2015), and some of these Bronze-Age culture groups probably expanded further toward higher elevation areas, perhaps reaching Yushu around $1000 \mathrm{BC}$. There is also another possibility that the population in the Yushu during this period was huntergatherers or pastoralists (Guedes 2015). According to the records in the Hou Han Shu-Xi Qiang Zhuan, Yushu was occupied by nomadic tribes called Xi Qiang peoples during the Shang (16001046 BC) to Han Dynasties (220 BC-AD 202). No date between $850 \mathrm{cal}$ BC and cal AD 540 was obtained in this study, suggesting that human inhabitation in the area was probably very sparse.

Humans inhabited the Yushu area before the establishment of the Tubo empire in the Tibetan Plateau (AD 618-842). Two ${ }^{14} \mathrm{C}$ dates from Labu range between 540 and 650 cal AD, corresponding to the transition period between the Wei Jin Southern and Northern Dynasties period (AD 220-581) and the Sui-Tang Dynasties (AD 581-907) in central China. Two other dates from Yarigei in Nangqian county range between cal AD 630 and cal AD 770, within the era of the Tubo empire. According to written records (Wang and Chen 1992), by the middle to late-6th century the Sumpa ( = Supi or Sunpo) peoples had already occupied the northern Tibetan Plateau, as far west as southern Xinjiang Province. Then the Tubo Empire became powerful and prosperous, conquering the Sumpa people and controlling the Yushu area until it collapsed in the middle-9th century (Yushu autonomous prefecture annals Codification Committee 2005). The Labu and Yarigei sites were likely occupied during the rule of the Sumpa tribe and the Tubo empire, as suggested by the archaeo dates (Figure 3; Table 1).

Humans occupied Barongbadang in Nangqian county between cal AD 1160 and 1250, corresponding to the Southern Song Dynasty (AD 1127-1279) of central China. As recorded in historical literature, during the middle-12th century AD a Tibetan tribe migrated to south Yushu area and established the Nangqian kingdom, which was highly autonomous but became affiliated with the Southern Song Dynasty in AD 1175, after which time the region began to be controlled by the central government in China (Yushu Autonomous Prefecture Annals Codification Committee 2005). According to these records and ${ }^{14} \mathrm{C}$ dates, Barongbadang was likely a village of the Nangqian kingdom. Three ${ }^{14} \mathrm{C}$ dates from Gala and Rongwaguo sites indicate that humans colonized the area between cal AD 1320 and 1620, corresponding to the Yuan (AD 1271-1368) and Ming (AD 1368-1644) dynasties in central China, which also accord well with historical documents. The central authority administered the Yushu autonomous prefecture during the Yuan Dynasty and strengthened its rule of the area during the Ming Dynasty. 


\section{How Did Humans Adapt to High-Altitude Environments in Yushu Area during the Late Holocene?}

To permanently colonize the Tibetan Plateau, humans needed to adapt physiologically to the hypoxic environment and obtain sufficient food resources from the Plateau's harsh high-cold environments. During the late Paleolithic period, humans seasonally occupied the Tibetan Plateau (Madsen et al. 1998, 2006; Brantingham et al. 2003, 2007; Brantingham and Gao 2006; Rhode et al. 2007, 2014). Limited wild animal resources of the alpine environment cannot alone sustain intensive and permanent human settlement. Humans began to settle extensively in the upper Yellow River valley headwaters at the margins of the northeast Tibetan Plateau between 5200 and 3600 BP (Figure 3), after the technology of millet cultivation was introduced to the area from the nearby Loess Plateau, which provided sufficient foods for intensive human settlement during that period (Chen et al. 2015). Millet growth is limited by cold temperature and growing degree days (Guedes et al. 2014), and these late Neolithic sites are mainly distributed below $2500 \mathrm{~m}$ asl (Figures $1 \mathrm{~b}$ and 3), except for a very few Neolithic sites such as the Karuo site ( $3100 \mathrm{~m}$ asl) in the southern Tibetan Plateau. After the introduction of barley and wheat to the northern margin of the Tibetan Plateau around 3600 BP (Dodson et al. 2013; Chen et al. 2015), humans gradually adopted these cold-tolerant exotic crops, and the combination of barley and wheat cultivation and sheep-herding facilitated human permanent settlement of areas up to $3400 \mathrm{~m}$ asl after $3600 \mathrm{BP}$ (Figure 3; Chen et al. 2015).

The cultivation of barley and wheat is still limited by cold temperature in higher areas of the Tibetan Plateau (Guedes 2015; Guedes et al. 2014, 2015), and barley and wheat farming as a primary subsistence strategy is usually restricted to below $3500 \mathrm{~m}$ asl ( $\mathrm{Hu}$ 1995). The lowest elevation of Yushu area is above $3500 \mathrm{~m}$ asl and the average elevation is above $4200 \mathrm{~m}$ asl, therefore barley cultivation is difficult and it is only auxiliary to the primary livelihood of pastoral nomadic livestock nowadays (Nori 2004). According to historical documents, pastoral nomadic tribes occupied Yushu before the unification of the Tibetan Plateau by the Tubo empire, and nomadic pastoralism continued to be the main subsistence strategy during the region of Tubo empire and Nangqian Kingdom (Gazangcaidan and Gesangmu 2000), even extending to later periods when the area was administered by the central authority (Ren 1985; Yushu Autonomous Prefecture Annals Codification Committee 2005; Qinghai Province Agricultural And Pastoral Office 2012; Wei 2013).

Our work provides archaeological evidence consistent with pastoral livelihoods being the primary subsistence strategy in the Yushu area during the late Holocene. Previous studies from Bronze age settlement sites of nomadic cultures in Hexi Corridor and east Xinjiang Province adjacent to northern margin of the Tibetan Plateau, suggest that raising of herding animals (such as horse, sheep, cattle, etc.), utilization of stone-constructed tombs, and rock painting, all may be used to trace the emergence of pastoral nomadic tribes (Xi 2007; Wang and Xi 2009). These suppositions were further examined in settlement sites between the Han Dynasty with Tang Dynasty in the Chang Tang Region of the Tibetan Plateau (Huo 2013).

Remains of domesticated animals including yak, sheep and horse were identified from Gala, Labu and Yarigei dated between AD 540 and 1620. Stone-constructed tombs were found at the Sariguo and Gala sites. Rock paintings were found at Maisong. Moreover, 10 other sites with stone-constructed structures and five sites with rock paintings were found in Yushu and Nangqian counties during the third national archaeological survey (unpublished data, personal communication with Mr. Linhai Cai). Based on this evidence and ${ }^{14} \mathrm{C}$ dating, we deduce that pastoral livelihoods were prevalent during the late Holocene in the high altitude areas of Yushu, 
corresponding to historical documents. Similarly, archaeological materials show that nomadic tribes had already built large-scale fortified settlements under the rule of pre-Buddhist kingdom of Zhang Zhung in the western Tibetan Plateau (Aldenderfer and Moyes 2005; Huo 2008).

Though recent studies indicate that agriculture innovation promoted permanent settlement above $3400 \mathrm{~m}$ asl (Guedes et al. 2014; Chen et al. 2015), the question of when pastoral livelihoods emerged in the high Plateau and their impact on human colonization of higher altitude areas, has not been well documented. According to currently published datasets, humans raised a variety of livestock including yak and sheep at the Qugong Bronze Age site $(3690 \mathrm{~m}$ asl) near Lhasa (Aldenderfer et al. 2004), suggesting humans engaged in nomadic production above $3600 \mathrm{~m}$ asl since $3400 \mathrm{BP}$, after migrating into high altitude areas after $3600 \mathrm{BP}$ (Figure 3). Our preliminary study in the Yushu area further implies that the emergence of pastoral livelihoods in that area facilitated human colonization above $3600 \mathrm{~m}$ asl in the late Holocene (Figure 3). The development and diversification of human subsistence strategies since the Neolithic period very likely promoted the stepwise expansion of human settlements upwards to the high altitudes of the central Tibetan Plateau (Figure 3).

\section{CONCLUSIONS}

Archaeological investigations and ${ }^{14} \mathrm{C}$ dating in the Yushu area of the Tibetan Plateau suggest that humans colonized the area during the late Holocene. Humans probably occasionally occupied the area during the Bronze Age period and inhabited the area more intensively from AD 540 to 1620 . Humans adopted pastoral livelihoods for adapting to the high-cold environment above $3600 \mathrm{~m}$ asl in Yushu since the Bronze Age, as indicated by the identification of yak, sheep and horse remains, stone-constructed tombs, and rock paintings.

Our work also suggests that sandy brown potteries and stone-constructed tombs were used in the Yushu area until the Ming dynasty at least, which make them unreliable for attributing archaeological sites containing them to be Bronze Age in the east-central Tibetan Plateau. Buried cultural deposits and ash pits cannot be readily found by archaeological survey in the Yushu area, and our preliminary study cannot provide a sufficient dataset for reconstructing detailed chronology and subsistence strategies for past human settlement in the area. More multidisciplinary studies from excavated sites in the Yushu area are needed to explore when and how humans colonized and adapted to the high elevation environments of the east-central Tibetan Plateau.

\section{ACKNOWLEDGMENTS}

This research was supported by the National Natural Science Foundation of China (Grant Nos. 41620104007 and 41671077), Fundamental Research Funds for the Central Universities (lzujbky-2015-k09, lzujbky-2016-159, and lzujbky-2016-251), as well as the 111 Program (\#B06026) of Chinese State Administration of Foreign Experts Affairs. We are really grateful to the editor and the two anonymous reviewers for their constructive suggestions and revisions.

\section{REFERENCES}

Aldenderfer M. 2006. Modelling plateau peoples: the early human use of the world's high plateaux. World Archaeology 38:357-70.

Aldenderfer M. 2011. Peopling the Tibetan plateau: insights from archaeology. High Altitude Medicine \& Biology 12:141-7.
Aldenderfer M, Moyes H. 2005. In the valley of the eagle: Zhang-zhung, Kyung-lung, and the preBuddhist sites of far western Tibet. Expedition 47:28-34.

Aldenderfer M, Zhang YN. 2004. The prehistory of the Tibetan Plateau to the seventh century 
a.d.: perspectives and research from China and the West since 1950. Journal of World Prehistory 18 (18): 155

Barton L. 2016. The cultural context of biological adaptation to high elevation Tibet. Archaeological Research in Asia 5:4-11.

Brantingham PJ, Gao X. 2006. Peopling of the northern Tibetan Plateau. World Archaeology 38(3):387-414.

Brantingham PJ, Ma H, Olsen JW, Gao X, Madsen DB, Rhode DE. 2003. Speculation on the timing and nature of Late Pleistocene hunter-gatherer colonization of the Tibetan Plateau. Chinese Science Bulletin 48(14):1510-6.

Brantingham PJ, Gao X, Olsen JW, Ma H, Rhode D, Zhang H, Madsen DB. 2007. A short chronology for the peopling of the Tibetan Plateau. Developments in Quaternary Sciences 9:129-50.

Bronk Ramsey C, Lee S. 2013. Recent and planned developments of the program OxCal. Radiocarbon 55(2-3):720-30.

Bureau of National Cultural Relics. 1996. Atlas of Chinese Cultural Relics-Fascicule of Qinghai Province. Beijing: China Cartographic Publishing House Press. In Chinese.

Bureau of National Cultural Relics. 2009. Guideline for Field Archaeological Work. Beijing: China Cartographic Publishing House Press. In Chinese.

Bureau of National Cultural Relics. 2010. Atlas of Chinese Cultural Relics-Fascicule of the Tibetan Autonomous Region. Beijing: Cultural Relics Publishing House. In Chinese.

Chen XP. 1989. Tang-Tibet Ancient Road. Xi'an: Sanqin Publishing House. In Chinese.

Chen FH, Dong GH, Zhang DJ, Liu XY, Jia X, An CB, Ma MM, Xie YW, Barton L, Ren XY, Zhao ZJ. 2015. Agriculture facilitated permanent human occupation of the Tibetan Plateau after 3600 BP. Science 347(6219):248-50.

Cherkinsky A, Quezada RF. 2014. Radiocarbon chronology of the Tlatoani site at Tlayacapan, Morelos, Mexico. Radiocarbon 56(2):501-10.

Dodson JR, Li X, Zhou X, Zhao K, Sun N, Atahan P. 2013. Origin and spread of wheat in China. Quaternary Science Reviews 72:108-11.

Dong G, Jia X, Elston R, Chen F, Li S, Wang L, Cai L, An C. 2013. Spatial and temporal variety of prehistoric sites and its influencing factors in the upper Yellow River valley, Qinghai Province, China. Journal of Archaeological Science 40:2538-46.

Dong G, Ren L, Jia X, Liu X, Dong S, Li H, Wang Z, Xiao Y, Chen F. 2016. Chronology and subsistence strategy of Nuomuhong culture in the Tibetan Plateau. Quaternary International 426:42-9.

Dong GH, Wang ZL, Ren LL, Matuzeviciute GM, Wang H, Ren XY, Chen FH. 2014. A comparative study of radiocarbon dating charcoal and charred seeds from the same flotation samples in the Late Neolithic and Bronze Age sites in the Gansu and Qinghai Provinces, Northwest China. Radiocarbon 56(1):157-63.
Dong W, An CB, Fan W, Li H, Zhao X. 2016. Stable isotopic detection of manual intervention among the faunal assemblage from a Majiayao site in NW China. Radiocarbon 58(02):311-21.

Gazangcaidan G. 2000. The Qinghai-Tibet Plateau Nomadic Culture. Lanzhou: Gansu Ethnic Publishing House. p 6. In Chinese.

Geyh MA, Schotterer U, Grosjean M. 1997. Temporal changes of the ${ }^{14} \mathrm{C}$ reservoir effect in lakes. Radiocarbon 40(2):921-31.

Guedes JD. 2015. Rethinking the spread of agriculture to the Tibetan Plateau. The Holocene 25(9): 1498-510.

Guedes JD, Jiang M, He K, Wu X, Jiang Z. 2013. Site of Baodun yields earliest evidence for the spread of rice and foxtail millet agriculture to southwest China. Antiquity 87(337):758-71.

Guedes JD, Lu H, Li Y, Spengler RN, Wu X, Aldenderfer MS. 2014. Moving agriculture onto the Tibetan plateau: the archaeobotanical evidence. Archaeological \& Anthropological Sciences 6(3):255-69.

Guedes JA, Lu H, Hein AM, Schmidt AH. 2015. Early evidence for the use of wheat and barley as staple crops on the margins of the Tibetan Plateau. Proceedings of the National Academy of Sciences 112(18):5625-30.

Guo Z, Liu K, Lu X, Ma H, Li K, Yuan J, Yuan S, $\mathrm{Wu}$ X, Liu X. 2001. AMS radiocarbon dating of Tianma-Qucun site in Shanxi, China. Radiocarbon 43(2B): 1109-14.

Guo Z, Liu K, Yuan S, Wu X, Li K, Lu X, Wang J, Ma H, Gao S, Xu L. 2005. AMS radiocarbon dating of the Fengxi site in Shaanxi, China. Radiocarbon 47(02):221-9.

Hu SJ. 1995. An Introduction to Agriculture of Tibet. Chengdu: Sichuan Publishing House of Science and Technology. In Chinese.

Huang WB. 1980. The faunal assemblage from the Neolithic site of Karuo in Changdu, Tibet. Vertebrata PalAsiatica 18(2): 163-8. In Chinese.

Hudson AM, Olsen JW, Quade J. 2014. Radiocarbon dating of interdune paleo-wetland deposits to constrain the age of mid-to-late Holocene Microlithic artifacts from the Zhongba site, southwestern Qinghai-Tibet Plateau. Geoarchaeology 29(1):33-46.

Huo W. 2008. The archaeological investigation of Kyung-lung Silver Castle site in glang-chen gtsang-po basin, western Tibet. In: Labapingcuo, editor. The Culture History of Western Tibet: Recent Research from the China Tibetology Research Center and the University of Vienna. Beijing: China Tibetan Press. In Chinese.

Huo W. 2013. The archaeological exploration on early settlement of Tibetan nomadic culture. Archaeo$\log y$ 4:57-67. In Chinese.

IA, CASS (Institute of Archaeology, Chinese Academy of Social Sciences) and CRBTAR (Cultural Relics Bureau of the Tibet Autonomous Region). 
1999. Lasa Qugong. Beijing: Encyclopedia of China Publishing House. p 237-43. In Chinese.

Liu H, Cui Y, Zuo X, Li H, Wang J, Zhang D, Zhang J, Dong G. 2016. Human settlements and plant utilization since the late prehistoric period in the Nujiang River valley, Southeast Tibetan Plateau. Archaeological Research in Asia 5:63-71.

Liu K, Han B, Guo Z, Wu X, Yuan S, Kutschera W, Ma H, Priller A, Steier P, Wild EM, Zhao C. 2005. AMS radiocarbon dating of bone samples from the Xinzhai site in China. Radiocarbon 47(01):21-5.

Madsen DB, Jingzen L, Elston RG, Cheng X, Bettinger RL, Kan G, Brantingham PJ, Kan Z. 1998. The loess/paleosol record and the nature of the Younger Dryas climate in Central China. Geoarchaeology 13(8):847-69.

Madsen DB, Haizhou M, Brantingham PJ, Xing G, Rhode D, Haiying Z, Olsen JW. 2006. The late Upper Paleolithic occupation of the northern Tibetan Plateau margin. Journal of Archaeological Science 33(10):1433-44.

Meyer MC, Aldenderfer MS, Wang Z, Hoffmann DL, Dahl JA, Degering D, Haas WR, Schlütz F. 2017. Permanent human occupation of the central Tibetan Plateau in the early Holocene. Science 355(6320):64-7.

Miehe G, Miehe S, Böhner J, Kaiser K, Hensen I, Madsen D, Liu J, Opgenoorth L. 2014. How old is the human footprint in the world's largest alpine ecosystem? A review of multiproxy records from the Tibetan Plateau from the ecologists' viewpoint. Quaternary Science Reviews 86:190-209.

Miller DJ. 1999. Nomads of the Tibetan Plateau rangelands in western China. Part Two. Pastoral production practices. Rangelands Archives 21(1):16-9.

Nori M. 2004. Hoofs on the Roof: Pastoral Livelihoods on the Qinghai-Tibetan Plateau, the Case of Chengduo County, Yushu Prefecture. Report. Asia Onlus. www.asiaonlus.org.

Qi X, Cui C, Peng Y, Zhang X, Yang Z, Zhong H, Zhang H, Xiang K, Cao X, Wang Y, Wu T. 2013. Genetic evidence of paleolithic colonization and neolithic expansion of modern humans on the tibetan plateau. Molecular Biology and Evolution 30(8):1761-78.

Qinghai Province Agricultural and Pastoral Office. 2012. Animal Husbandry Annals. Xining: Qinghai province statistics press. In Chinese.

Qiu Q, Wang L, Wang K, Yang Y, Ma T, Wang Z, Zhang X, Ni Z, Hou F, Long R, Abbott R. 2015. Yak whole-genome resequencing reveals domestication signatures and prehistoric population expansions. Nature Communications. DOI: 10.1038/ ncomms 10283.

Reimer PJ, Bard E, Bayliss A, Beck JW, Blackwell PG, Bronk Ramsey C, Buck CE, Cheng H, Edwards RL, Friedrich M, Grootes PM. 2013. IntCal13 and Marine13 radiocarbon age calibration curves 0-50,000 years cal BP. Radiocarbon 55(4):1869-87.
Ren JZ. 1985. Grassland Survey and Planning. Beijing: China Agriculture Press. In Chinese.

Rhode D, Haiying Z, Madsen DB, Xing G, Brantingham PJ, Haizhou M, Olsen JW. 2007. Epipaleolithic/early Neolithic settlements at Qinghai Lake, western China. Journal of Archaeological Science 34(4):600-12.

Rhode D, Brantingham PJ, Perreault C, Madsen DB. 2014. Mind the gaps: testing for hiatuses in regional radiocarbon date sequences. Journal of Archaeological Science 52:567-77.

Salazar-García DC, García-Puchol O, de MiguelIbáñez MP, Talamo S. 2016. Earliest evidence of Neolithic collective burials from eastern Iberia: radiocarbon dating at the archaeological site of Les Llometes (Alicante, Spain). Radiocarbon 58(3): 679-92.

Schlütz F, Lehmkuhl F. 2009. Holocene climatic change and the nomadic Anthropocene in Eastern Tibet: palynological and geomorphological results from the Nianbaoyeze Mountains. Quaternary Science Reviews 28(15):1449-71.

Shi KP. 1988. Economic Geography of Qinghai Province. Beijing: Xinhua Publishing House. In Chinese.

Sun Y, Lai Z, Madsen D, Hou G. 2012. Luminescence dating of a hearth from the archaeological site of Jiangxigou in the Qinghai Lake area of the northeastern Qinghai-Tibetan Plateau. Quaternary Geochronology 12:107-10.

Tang H, Zhou C, Li Y, Liang Z. 2013. A new discovery of microlithic information at the entrance to the Northern Qingzang Plateau of the Kunlun Mountains of Qinghai. Chinese Science Bulletin 58:247-53.

Wang JX, Xi L. 2009. The archaeological study on early settlement of nomadic culture in East Tianshan Mountain region. Archaeology 1:28-37. In Chinese.

Wang Y, Chen J. 1992. Dunhuang Tibetan Historical Instruments. Revised edition. Beijing: The Ethnic Publishing House. p 146-7. In Tibetan and Chinese.

Wei YQ. 2013. Impacts of climate change on the animal husbandry in the Tibetan Plateau [PhD thesis]. University of Chinese Academy of Sciences, China. In Chinese.

Xi L. 2007. The Study on the ancient nomadic archaeological remains in Mazong mountainous area [master's thesis]. Northwest University, China. In Chinese.

Yuan BY, Huang WW, Zhang D. 2007. New evidence for human occupation of the northern Tibetan Plateau, China during the Late Pleistocene. Chinese Science Bulletin 52(19):2675-9.

Yushu Autonomous Prefecture Annals Codification Committee. 2005. Yushu autonomous prefecture annals. Xi'an: Sanqin Publishing House. In Chinese.

Zhang DD, Li SH. 2002. Optical dating of Tibetan human hand-and footprints: an implication for 


\section{L Ren et al.}

the palaeoenvironment of the last glaciation of the Tibetan Plateau. Geophysical Research Letters 29(5):16-1-16-3.

Zhang ZX. 2009. Geography of Qinghai Province. Beijing: Science Press. In Chinese.

Zhao M, Kong QP, Wang HW, Peng MS, Xie XD, Wang WZ, Duan JG, Cai MC, Zhao SN, Tu YQ,
Wu SF. 2009. Mitochondrial genome evidence reveals successful Late Paleolithic settlement on the Tibetan Plateau. Proceedings of the National Academy of Sciences 106(50):21230-5.

Zhao ZJ. 2009. Eastward spread of wheat into China-new data and new issues. Chinese Archaeology 9(1):1-9. 